\title{
Isolated metastases of hepatocellular carcinoma in the right atrium: Case report and review of the literature
}

\author{
MANRI KAWAKAMI ${ }^{1}$, MASAHIKO KODA ${ }^{1}$, MARI MANDAI $^{1}$, KEIKO HOSHO ${ }^{1}$, \\ YOSHIKAZU MURAWAKI $^{1}$, WAKAKO ODA ${ }^{2}$ and KAZUHIKO HAYASHI ${ }^{2}$ \\ ${ }^{1}$ Department of Multidisciplinary Internal Medicine, Division of Medicine and Clinical Science, School of Medicine; \\ ${ }^{2}$ Division of Molecular Pathology, Tottori University, Yonago 683-8504, Japan
}

Received November 28, 2012; Accepted February 21, 2013

DOI: $10.3892 / \mathrm{ol} .2013 .1240$

\begin{abstract}
The aim of this study was to clarify the clinical features of patients with isolated HCC metastases to the heart. A 66-year-old female hospitalized with a hepatocellular carcinoma (HCC) ranging from the right to the left lobe and with a tumor thrombus in the main portal vein, was treated with intraarterial cisplatin, 5-fluouracil, adriamycin and mitomycin. Computed tomography (CT) one month later revealed that the HCC had progressed with multiple lung metastases and moderate ascites. The patient had no symptoms. Magnetic resonance imaging (MRI) and echocardiography revealed a round, movable tumor with a diameter of $2 \mathrm{~cm}$ in the right atrium (RA). The patient succumbed to HCC five months later. An autopsy revealed $\mathrm{HCC}$ with portal tumor thrombi and metastases to the lungs, inferior vena cava (IVC) and RA. The metastases in the RA and IVC were not continous with the intrahepatic tumor and were histologically attached to the endocardium and endothelium, respectively. An isolated metastasis of a HCC of the RA and IVC is extremely rare. In conclusion, although the majority of isolated metastases of HCC to the heart were diagnosed by echocardiography and were treated with mainly surgery, they had poor prognosis. The echocardiography should be performed for patients with advanced HCC. A novel treatment including molecular targeted drugs is required.
\end{abstract}

Correspondence to: Dr Masahiko Koda, Department of Multidisciplinary Internal Medicine, Division of Medicine and Clinical Science, Tottori University School of Medicine, 36-1 Nishicho, Yonago 683-8504, Japan

E-mail: masakoda@grape.med.tottori-u.ac.jp

Abbreviations: CT, computed tomography; HCC, hepatocellular carcinoma; MRI, magnetic resonance imaging

Key words: hepatocellular carcinoma, isolated atrial metastasis, prognosis

\section{Introduction}

Hepatocellular carcinomas (HCCs) frequently invade the vascular system at points such as the portal and hepatic veins. The results of autopsy studies indicate a $2.7-4.1 \%$ incidence of atrial metastases of HCC $(1,2)$. A correct diagnosis is important in the clinical setting since cardiac metastases are able to induce sudden cardiac arrest. The majority of metastases develop as continuous extensions of a tumor thrombus in the hepatic vein. However, isolated cardiac metastases are extremely rare. The present study describes a 66 -year-old female with an isolated right atrial metastasis of a HCC and reviews previous published studies, treatments and outcomes in similar patients. Written informed consent was obtained from the patients' family.

\section{Case report}

A 66-year-old female was diagnosed with chronic hepatitis type B and HCC in May 2004. The patient had no jaundice, vascular spiders, palmar erythema or cardiac murmurs. A hard mass was palpable from the right hypochondrium to the epigastrium. The laboratory results (normal ranges in parentheses) were as follows: total bilirubin, $0.9 \mathrm{mg} / \mathrm{dl}(0.2-1.2 \mathrm{mg} / \mathrm{dl}) ;$ aspartate aminotransferase, $115 \mathrm{IU} / \mathrm{l}$ (5-40 IU/1); alanine aminotransferase, $105 \mathrm{IU} / 1$ (5-47 IU/1); alkaline phosphatase $491 \mathrm{IU} / 1$ (111-295 IU/1); and lactate dehydrogenase, 199 IU/1 (100-225 IU/1). The patient was positive for the hepatitis B surface antigen and e-antibodies. The serum $\alpha$-fetoprotein and des- $\gamma$-carboxy prothrombin levels were elevated to $687,460 \mathrm{ng} / \mathrm{ml}$ (normal range, $<13.2 \mathrm{ng} / \mathrm{ml}$ ) and $1037 \mathrm{mAU} / \mathrm{ml}$ (normal range, $<40 \mathrm{mAU} / \mathrm{ml}$ ), respectively.

Abdominal sonography and computed tomography (CT) imaging revealed a large mass reaching from the right to the left lobe and a tumor thrombus in the main portal vein (Fig. 1A and B). Angiography revealed a hypervascular tumor in the right lobe exhibiting the thread and streak sign. No metastases were identified in the right atrium (RA) or inferior vena cava (IVC) prior to starting intraarterial chemotherapy with cisplatin, 5-fluouracil, adriamycin and mitomycin.

An enhanced CT in July, 2004, showed that the HCC had progressed and that multiple lung metastases had developed with moderate ascites. Magnetic resonance imaging (MRI) 

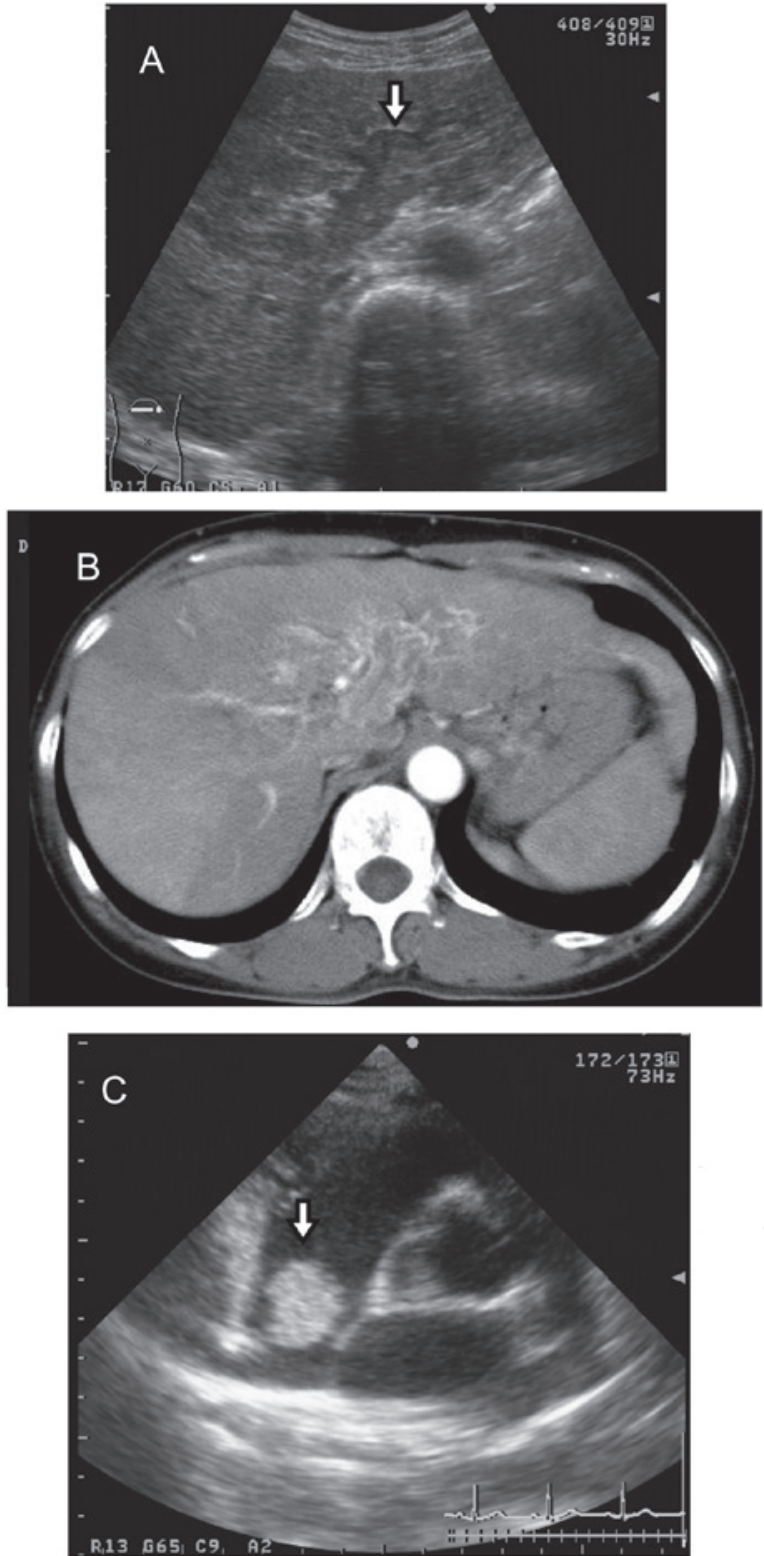

Figure 1. Imaging findings. (A) Abdominal sonographic image showing ill-defined large isoechoic mass with portal thrombus (arrow). (B) Computed tomography (CT) image showing ill-defined large heterogeneous mass occupying the bilateral liver lobes, and portal thrombus accompanying a cavernous transformation. (C) Transthoracic echocardiography image showing a round, movable tumor of a $2-\mathrm{cm}$ diameter in the right atrium (RA; arrow).

and echocardiography revealed a round, movable tumor with a diameter of $2 \mathrm{~cm}$ in the RA (Fig. 1C), but no tumor thrombus in the IVC. The atrial tumor was not continuous with the intrahepatic HCC. Anticoagulation therapy with warfarin was administered, however the patient succumbed to hepatic failure five months later (Fig. 2).

An autopsy revealed diffuse-type HCC in the bilateral lobes of the liver that weighed $1,365 \mathrm{~g}$, with a tumor thrombus in the main trunk of the portal vein, bilateral multiple lung metastases and tumor thrombi in the artery of the right upper lung. A yellowish irregular-surfaced mass with a diameter of $10 \mathrm{~mm}$ located in the RA, and a similar small independent mass in the IVC (Fig. 3), were discontinuous with the intrahepatic HCC. Histologically, the intrahepatic and right atrial

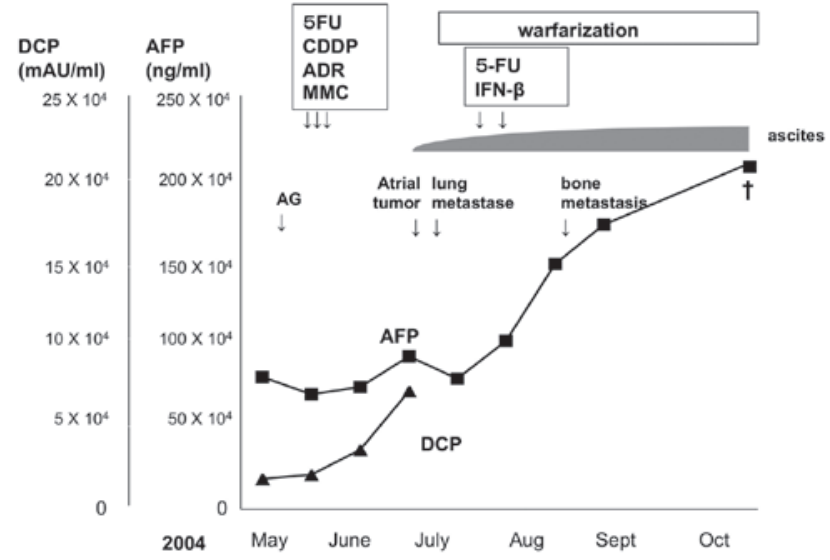

Figure 2. Clinical course of the patient. ADR, adriamycin; AFP, $\alpha$-fetoprotein; AG, angiography; CDDP, cisplatin; DCP, des- $\gamma$-carboxy prothrombin; $5-\mathrm{FU}$, 5-fluouracil; IFN- $\beta$, interferon $\beta$; MMC, mitomycin C.

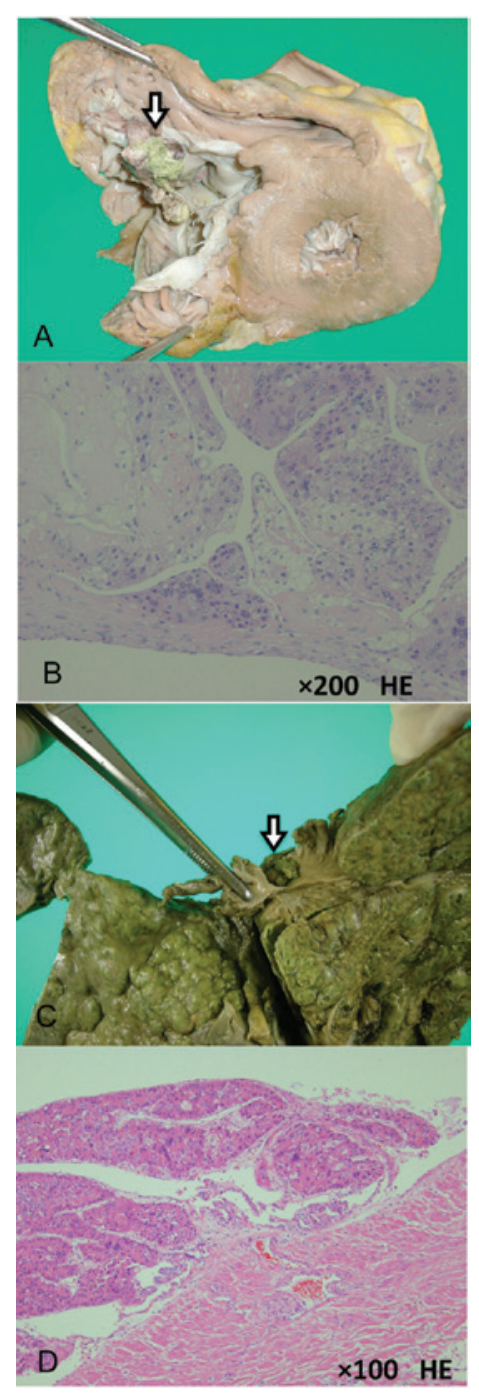

Figure 3. Appearance and diagnosis of autopsy specimen. (A) Yellowish tumor with irregular surface (arrow) located in the right atrium (RA) of the heart specimen at autopsy. (B) Right atrial tumor attached to the endocardium diagnosed as a moderately differentiated HCC of trabecular type (hematoxylin-eosin stain). (C) Greenish tumor with irregular surface (arrow) located in inferior vena cava (IVC), discontinuous with the intrahepatic HCC. (D) Tumor attached to the endothelium in the IVC, pathologically diagnosed as a moderately differentiated $\mathrm{HCC}$ of trabecular type (hematoxylin-eosin stain). HCC, hepatocellular carcinoma. 
Table I. Patients with isolated HCC metastases to the heart.

\begin{tabular}{|c|c|c|c|c|c|c|c|c|c|}
\hline Case & Ref. & $\begin{array}{c}\text { Age } \\
\text { (years), } \\
\text { gender }\end{array}$ & $\begin{array}{l}\text { Diagnosis } \\
\text { stage }\end{array}$ & Symptoms & $\begin{array}{l}\text { Pretreatment for } \\
\text { cardiac metastases }\end{array}$ & Pathology & $\begin{array}{l}\text { Location of } \\
\text { initial HCC }\end{array}$ & $\begin{array}{c}\text { Treatment for } \\
\text { cardiac metastase }\end{array}$ & Prognosis \\
\hline 1 & 3 & $52 \mathrm{M}$ & Autopsy & $\begin{array}{c}\text { Dyspnea, } \\
\text { heart murmur }\end{array}$ & None & NS & RA, endocardium & Supportive care & $\begin{array}{l}\text { Succumbed } \\
\text { after } 1 \text { month }\end{array}$ \\
\hline 2 & 4 & $55 \mathrm{M}$ & Autopsy & $\begin{array}{l}\text { Dyspnea, } \\
\text { cyanosis }\end{array}$ & None & Ed II-III & $\begin{array}{c}\mathrm{RA}, \mathrm{LA}, \\
\text { endocardium }\end{array}$ & Supportive care & $\begin{array}{l}\text { Succumbed } \\
\text { after } 1 \text { month }\end{array}$ \\
\hline 3 & 5 & $67 \mathrm{M}$ & Autopsy & $\begin{array}{l}\text { Fever, cough, } \\
\text { chest discomfort }\end{array}$ & None & Ed III & LV, epicardium & Supportive care & $\begin{array}{l}\text { Succumbed } \\
\text { after } 2 \text { months }\end{array}$ \\
\hline 4 & 6 & $73 \mathrm{M}$ & Autopsy & Heart murmur & None & Ed I-II & RA, RV & TAE & $\begin{array}{l}\text { Succumbed } \\
\text { after } 1 \text { month }\end{array}$ \\
\hline 5 & 7 & $51 \mathrm{M}$ & $\mathrm{CT}$ & Dyspnea, palpitation & Hepatectomy & NS & $\mathrm{RV}$, myocardium & Surgery & Succumbed \\
\hline 6 & 7 & $29 \mathrm{M}$ & UCG & Dyspnea & Hepatectomy & Ed II & LA & Chemotherapy & Succumbed \\
\hline 7 & 8 & $71 \mathrm{M}$ & Autopsy & $\begin{array}{l}\text { Consciousness } \\
\text { disorder }\end{array}$ & Chemotherapy & Ed II & $\begin{array}{c}\mathrm{RV}, \mathrm{LV}, \\
\text { myocardium }\end{array}$ & NS & $\begin{array}{l}\text { Succumbed } \\
\text { after } 0.5 \text { months }\end{array}$ \\
\hline 8 & 9 & $76 \mathrm{M}$ & UCG & Dyspnea & $\begin{array}{c}\text { Hepatectomy, } \\
\text { MCT, chemotherapy }\end{array}$ & Ed I-II & $\mathrm{RV}$, myocardium & Surgery & $\begin{array}{l}\text { Succumbed } \\
\text { after } 6 \text { months }\end{array}$ \\
\hline 9 & 10 & $49 \mathrm{~F}$ & UCG & $\begin{array}{c}\text { Dyspnea, palpitation, } \\
\text { heart murmur }\end{array}$ & Hepatectomy & Ed I-II & $\mathrm{RV}$, myocardium & Surgery & $\begin{array}{c}\text { Alive at } \\
21 \text { months }\end{array}$ \\
\hline 10 & 11 & $67 \mathrm{~F}$ & UCG & $\begin{array}{c}\text { Dyspnea, } \\
\text { heart murmur }\end{array}$ & Hepatectomy & Ed II & RV & TAE & $\begin{array}{l}\text { Alive at } \\
3 \text { months }\end{array}$ \\
\hline 11 & 12 & $43 \mathrm{M}$ & $\mathrm{UCG}, \mathrm{CT}$ & Dyspnea, cough & Hepatectomy & Ed I-II & RV & Supportive care & $\begin{array}{c}\text { Succumbed } \\
\text { after } 20 \text { days }\end{array}$ \\
\hline 12 & 13 & $45 \mathrm{M}$ & UCG, CT & $\begin{array}{l}\text { Dyspnea, } \\
\text { dizziness }\end{array}$ & Hepatectomy & NS & RV & Surgery & $\begin{array}{l}\text { Alive at } \\
3 \text { months }\end{array}$ \\
\hline 13 & 14 & $65 \mathrm{~F}$ & $\mathrm{CT}$ & Dyspnea & Hepatectomy & NS & RV & Surgery & $\begin{array}{l}\text { Succumbed } \\
\text { after } 3 \text { months }\end{array}$ \\
\hline 14 & 15 & $45 \mathrm{~F}$ & UCG & $\begin{array}{l}\text { Dyspnea, } \\
\text { syncope }\end{array}$ & $\begin{array}{l}\text { Hepatectomy, } \\
\text { TAE }\end{array}$ & Ed II & RV & Surgery & $\begin{array}{l}\text { Succumbed } \\
\text { after } 4 \text { months }\end{array}$ \\
\hline 15 & 16 & $63 \mathrm{~F}$ & UGC & Dyspnea & TAE & Ed IV & RA & Surgery & NS \\
\hline 16 & 17 & $74 \mathrm{~F}$ & UCG & Dyspnea, syncope & TAE & NS & RV & Surgery & $\begin{array}{l}\text { Succumbed } \\
\text { after } 4 \text { months }\end{array}$ \\
\hline 17 & $\begin{array}{l}\text { Present } \\
\text { study }\end{array}$ & $66 \mathrm{~F}$ & UCG & None & Chemotherapy & Ed II & $\begin{array}{c}\text { RA, } \\
\text { endocardium }\end{array}$ & TAI & $\begin{array}{c}\text { Succumbed } \\
\text { after } 5 \text { months }\end{array}$ \\
\hline
\end{tabular}

UCG, ultrasound cardiography; MCT, microwave coagulation therapy; TAE, transcatheter arterial embolization; Ed, Edmondson; NS, not stated; RA, right atrium; RV, right ventricle; LA, left atrium; LV, left ventricle; TAI, transcatheter arterial infusion chemotherapy; HCC, hepatocellular carcinoma.

tumors were moderately differentiated HCCs. The right atrial tumor was fixed to the atrial wall and arose from sites on the endocardium of the RA (Fig. 3A and B). The small tumor in the IVC was similarly fixed to the endothelium (Fig. 3C and D).

\section{Discussion}

The mechanism of cardiac metastases is as a contiguous extension from the intrahepatic HCC via a tumor thrombus to the IVC or by lymphatic or hematologous spread. The majority of cardiac metastases are direct and contiguous extensions of the intrahepatic HCC. Isolated cardiac metastases that are discontinuous with an intrahepatic HCC are extremely rare. The literature was searched for descriptions of isolated cardiac metastases of HCC and 17 patients were identified (Table I) with a mean age of $58 \pm 13$ years. In total, 15 patients (88.2\%) had symptoms, with $13(76.5 \%)$ suffering dyspnea. Intermittent obstruction by tumors in the cardiac cavity led to the symptoms of ball valve thrombus syndrome, which is able to induce sudden cardiac arrest (18). However, in the present study, the patient had no symptoms since the diameter of the tumor was $2 \mathrm{~cm}$.

Extracorporal echocardiography was useful for detecting the atrial tumor in the present case. Kanematsu et al (19) described a tumor thrombus of HCC in the IVC detected by CT and MRI. Yoshitomi et al (20) and Van Camp et al (21) found transesophageal echocardiography useful. In theses studies, cardiac metastases were diagnosed by UCG and CT in $10(58.8 \%)$ and $4(23.5 \%)$ patients, respectively. Cardiac metastases were identified at autopsy in the early cases. The HCC was initially treated in 13 (76.5\%) of the 17 patients [hepatectomy, $\mathrm{n}=9$; transcatheter arterial embolization (TAE), $\mathrm{n}=3$; chemotherapy, $\mathrm{n}=3$ ] and then the cardiac metastases were identified.

In the present study, the tumors in the RA and IVC were not continuous growths from the intrahepatic HCC in 
the patient. The two tumors were individually isolated and attached to the endocardium or endothelium, respectively. This metastatic pathway was considered to be comprised of two mechanisms. The first was the seeding of a blood flow onto the endocardium or endothelium from the intrahepatic HCC and the second was cancer embolisms of the small vessels under the endocardium and endothelium via arterial systemic spread. However, in the published cases, the mechanism associated with the metastases could not be clarified. Cardiac metastases were notably located in the right ventricle (RV), RA and left ventricle (LV) in 10 (58.8\%), 5 (29.4\%) and $2(11.8 \%)$ patients, respectively. A greater number of metastases had invaded the RV than the RA. These findings indicate that the main mechanism is embolism via arterial systemic spread as massive myocardial involvement was described in 4 patients.

Surgical (22) or non-surgical approaches, including TAE (23), transcatheter arterial infusion chemotherapy (TAI) (24) and radiotherapy (25), have been undertaken to treat IVC/RA metastases. In the selected published cases, eight $(47.1 \%)$ out of 17 patients underwent surgery to relieve symptoms. In the present study, the patient underwent TAI only, but succumbed to HCC progression five months later. Overall, all the patients had an extremely poor prognosis regardless of the treatment strategy. Chang et al (26) reported that thalidomide is a useful angiogenesis inhibitor for IVC/RA metastases and new molecular target drugs, such as Sorafenib, have since emerged (27). However, further studies involving a larger cohort of patients with IVC/RA tumor thrombi are required.

\section{References}

1. Kojiro M, Nakahara H, Sugihara S, Murakami T, Nakashima T and Kawasaki H: Hepatocellular carcinoma with intra-atrial tumor growth. A clinicopathologic study of 18 autopsy cases. Arch Pathol Lab Med 108: 989-992, 1984.

2. MacDonald RA: Primary carcinoma of the liver; a clinicopathologic study of one hundred eight cases. AMA Arch Intern Med 99: 266-279, 1957.

3. Kato Y, Kurosaki M, Kobayashi K, Sugimoto T and Takada A: Liver cancer associated with a large spheric thrombus caused by tumor in the right atrium of the heart. Naika 28: 349-353, 1971 (In Japanese).

4. Takigami S, Komai Y, Lai Y-S, et al: An autopsy case of minute hepatoma accompanied by a large intraatrial tumor embolus. Acta Hepat Jap 21: 478-486, 1980 (In Japanese).

5. Yoshioka K, Izuchi M, Okayama M, et al: An autopsied case of hepatocellular carcinoma with metastases to the heart and spleen. Acta Hepat Jap 24: 909-913, 1983 (In Japanese).

6. Miura Y, Kondo K, Watanabe T, et al: An autopsy case of hepatocellular carcinoma with tumor thrombus in the right atrium. Nihon Shokakibyo Gakkai Zasshi 86: 2460-2463, 1989.

7. Lei MH, Ko YL, Kuan P, Lien WP and Chen DS: Metastases of hepatocellular carcinoma to the heart: unusual patterns in three cases with antemortem diagnosis. J Formos Med Assoc 91: 457-461, 1992

8. Kimitsuki H, Nagasaki Y, Yamashita Y, Kurohiji T, Kakegawa T and Nakashima T: An autopsied case of hepatocellular carcinoma with cardiac metastasis. Acta Hepat Jap 35: 629-632, 1994 (In Japanese).
9. Shiota S, Konishi I, Sato N, et al: A case of hepatocellular carcinoma with metastases to the right ventricle of the heart. Jpn J Clin Surg 61: 1542-1546, 2000 (In Japanese).

10. Murakawa T, Takamoto S, Ezure M, Ono M, Kawauchi M and Tanaka O: Metastatic hepatocellular carcinoma obstructing the right ventricular outflow tract. Jpn J Thorac Cardiovasc Surg 48: 516-519, 2000.

11. Kotani E, Kiuchi K, Takayama M, et al: Effectiveness of transcoronary chemoembolization for metastatic right ventricular tumor derived from hepatocellular carcinoma. Chest 117: $287-289,2000$

12. Longo R, Mocini D, Santini M, et al: Unusual sites of metastatic malignancy: case 1. Cardiac metastasis in hepatocellular carcinoma. J Clin Oncol 22: 5012-5014, 2004.

13. Lin TY, Chiu KM, Chien CY, Ming C, Wang MJ and Chu SH: Case 1. Right ventricular outflow obstruction caused by metastatic hepatocellular carcinoma. J Clin Oncol 22: 1152-1153, 2004.

14. Chieng $\mathrm{SH}$, Lin $\mathrm{CH}$, Lu MJ and Hung CR: Intracavitary metastatic hepatocellular carcinoma of the right ventricle. Thorac Cardiovasc Surg 53: 123-125, 2005.

15. Liu YC, Hung CS, Chan SY, Chen YW, Shun CT and Lai LP: Asymptomatic metastasis of hepatocellular carcinoma into the right ventricular cavity presenting with electrocardiographic changes. Acta Cardiol Sin 22: 180-183, 2006.

16. Sekine Y, Kitano M, Akimoto T and Matsuda K: Isolated intracavitary metastatic hepatocellular carcinoma of the right atrium without inferior vena cava involvement: report of a case. Kyobu Geka 60: 504-507, 2007 (In Japanese).

17. Kan CB, Chang RY and Chen CK: Isolated right ventricular intracavitary metastasis of hepatocellular carcinoma in a 74-year-old woman. J Clin Med Assoc 71: 318-320, 2008.

18. Sung AD, Cheng S, Moslehi J, Scully EP, Prior JM and Loscalzo J: Hepatocellular carcinoma with intracavitary cardiac involvement: a case report and review of the literature. Am J Cardiol 102: 643-645, 2008.

19. Kanematsu M, Imaeda T, Minowa H, et al: Hepatocellular carcinoma with tumor thrombus in the inferior vena cava and right atrium. Abdom Imaging 19: 13-316, 1994.

20. Yoshitomi Y, Kojima S, Sugi T, et al: Echocardiography of a right atrial mass in hepatocellular carcinoma. Heart Vessels 13: 45-48, 1998.

21. Van Camp G, Abdulsater J, Cosyns B, Liebens I and Vandenbossche JL: Transesophageal echocardiography of right atrial metastasis of a hepatocellular carcinoma. Chest 105: 945-947, 1994.

22. Yoshidome H, Takeuchi D, Kimura F, et al: Treatment strategy for hepatocellular carcinoma with major portal vein or inferior vena cava invasion: a single institution experience. J Am Coll Surg 212: 796-803, 2011.

23. Mizuno S, Kato H, Azumi Y, et al: Total vascular hepatic exclusion for tumor resection: a new approach to the intrathoracic inferior vena cava through the abdominal cavity by cutting the diaphragm vertically without cutting the pericardium. J Hepatobiliary Pancreat Sci 17: 197-202, 2010.

24. Murakami E, Aikata H, Miyaki D, et al: Hepatic arterial infusion chemotherapy using 5-fluorouracil and systemic interferon- $\alpha$ for advanced hepatocellular carcinoma in combination with or without three-dimensional conformal radiotherapy to venous tumor thrombosis in hepatic vein or inferior vena cava. Hepatol Res 42: 442-453, 2012.

25. Komatsu S, Fukumoto T, Demizu Y, et al: The effectiveness of particle radiotherapy for hepatocellular carcinoma associated with inferior vena cava tumor thrombus. J Gastroenterol 46: 913-920, 2011.

26. Chang JY, Ka WS, Chao TY, Liu TW, Chuang TR and Chen LT: Hepatocellular carcinoma with intra-atrial tumor thrombi. A report of three cases responsive to thalidomide treatment and literature review. Oncology 67: 320-326, 2004.

27. Llovet JM, Ricci S, Mazzaferro V, et al; SHARP Investigators Study Group: Sorafenib in advanced hepatocellular carcinoma. N Engl J Med 359: 378-390, 2008. 